\title{
Produção de antígeno e separação da proteína p28 por microfiltragem seriada para sorodiagnóstico da artrite encefalite caprina por ensaio imunoenzimático
}

\author{
[Production of antigen and p28 protein separation by microfiltration serial for serodiagnosis \\ of caprine arthritis encephalitis by enzyme immunoassay] \\ L.A.O. Alves $^{1}$, M.F.S. Teixeira ${ }^{1}$, A.A. Pinheiro $^{2}$, R.R. Pinheiro ${ }^{2}$, R.P. Dias $^{1}$, R.L.L. Brito ${ }^{3}$, \\ C.A.F. Lopes Júnior ${ }^{1}$, R.Q. Bezerra Júnior ${ }^{1}$, D.A.A. Azevedo ${ }^{2}$ \\ ${ }^{1}$ Faculdade de Veterinária - Universidade Estadual do Ceará - Fortaleza, CE \\ ${ }^{2}$ Empresa Brasileira de Pesquisa Agropecuária - Embrapa Caprinos e Ovinos - Sobral, CE \\ ${ }^{3}$ Faculdade de Agricultura e Ciências Veterinárias - Universidade Estadual Paulista - UNESP - São Paulo, SP
}

\section{RESUMO}

Este estudo teve como objetivo produzir um antígeno $(\mathrm{Ag})$ a partir de cultura de células de membrana sinovial caprina (MSC) infectadas com o vírus de artrite encefalite caprina (CAEV), pela técnica de microfiltração seriada, substituindo a ultracentrifugação em colchão de sacarose (UCCS) para utilização em ELISA indireto (ELISA-i). Amostras de 188 soros caprinos, que previamente foram testados pelo Western blot (WB) com Ag UCCS, foram submetidas à análise pelo ELISA-i com o novo antígeno produzido, que mostrou concordância de $92 \%$ em relação ao antígeno UCCS. A sensibilidade e a especificidade do ELISA em relação ao WB foram de $95,6 \%$ e $88,5 \%$, respectivamente. A nova técnica, criada a partir de microfiltrações, mostrou-se efetiva e de baixo custo para o diagnóstico sorológico de anticorpos para CAEV em comparação ao antígeno ultracentrifugado, e constitui uma alternativa viável para produção de antígeno purificado de lentivírus de pequenos ruminantes.

Palavras-chave: caprino, CAEV, ELISA, lentivírus de pequenos ruminantes, Western blot

\begin{abstract}
This study aimed to produce an antigen (Ag) from the culture of goat synovial membrane cells (MSC) infected by CAEV through serial microfiltering technique replacing ultra ultracentrifugation in sacarosis Mattress (UCCS) for the indirect diagnosis ELISA tests (i ELISA). Samples of 188 sera from goats previously examined by Western Blot (WB) with Ag UCCS were submitted to analysis by i ELISA with new antigen produced, demonstrating an accordance of $92 \%$ in relation to UCCS antigen. The specificity and sensitivity relating to WB were of $95,65 \%$ and $88,5 \%$ respectively. The new technique created from the microfiltering is effective and with low cost for the serological antibodies diagnosis of CAEV comparing to the ultracentrifuged one, presenting, therefore, as a viable alternative for purified antigen of lentivirus in small ruminants.
\end{abstract}

Keywords: caprine, CAEV, ELISA, lentivirus, Western blot

\section{INTRODUÇÃO}

A artrite encefalite caprina (CAE) é uma enfermidade multissistêmica, de caráter crônico e debilitante, causada por um RNA vírus que pertence ao gênero Lentivírus, da família Retroviridae, subfamília Orthoretrovirinae
(ICTV, 2009). Apresenta como principais formas clínicas: artrite, pneumonia e mastite, observadas em animais adultos, e mais raramente a leucoencefalomielite, em caprinos jovens (Pugh, 2004), e não possui tratamento ou vacinação como ferramenta de controle (Peterhans, 2004; Konishi et al., 2011).

Recebido em 4 de agosto de 2011 
Os lentivírus de pequenos ruminantes (SRLV) caracterizam-se por realizarem replicação em células do sistema monócito-fagocitário, perdurando no interior dos monócitos e macrófagos por um intervalo de tempo prolongado, do momento da infecção até o aparecimento de sintomas. Devido a esse fato, o diagnóstico baseado no exame clínico é limitado, sendo necessária a detecção de anticorpos específicos por testes sorológicos (Pasick, 1998).

Dentre os testes disponíveis, a imunodifusão em gel de agarose (IDGA) é o mais utilizado para o diagnóstico de infecção por lentivírus (Simard e Briscoe, 1990a; Knowles et al., 1990). Este, no entanto, é uma técnica de baixa sensibilidade em níveis reduzidos de anticorpos (Keen et al., 1995; McConnell et al., 1998). Alternativamente, tem-se utilizado o ensaio imunoenzimático indireto por ser mais sensível do que o IDGA, porém ele apresenta outras desvantagens, como custo de produção e a necessidade da utilização de antígenos mais purificados do que os empregados no IDGA (Akerstrom et al., 1985; Pinheiro et al., 2010).

$\mathrm{Na}$ purificação de antígenos para padronização do teste ELISA-i, muitos protocolos são utilizados. Estes empregam, de forma simples ou combinada, as seguintes técnicas: centrifugação simples, centrifugação e ultracentrifugação em gradiente contínuo ou descontínuo de sacarose, filtração pressurizada, cromatografias de troca iônica e de afinidade, concentração e precipitação com polietilenoglicol 8.000 (PEG 8.000) (Zanoni et al., 1994; Simard et al., 2001). Contudo, a maioria desses protocolos é demorada e onerosa, já que possui várias etapas de processamento e requer uma construção laboratorial sofisticada.

Este trabalho tem como objetivo desenvolver e padronizar um método rápido, prático e menos oneroso para produção de antígenos do vírus da artrite encefalite caprina, pela separação da porção proteica $\mathrm{p} 28$, por meio de microfiltragens seriadas que possibilitem o diagnóstico por imunoensaios, bem como comparar tais antígenos com aqueles produzidos por ultracentrifugação em colchão de sacarose.

\section{MATERIAL E MÉTODOS}

Para a produção do antígeno, foram utilizados sobrenadantes de cultivo de células de MSC oriundas de articulações cárpicas, conforme definido por Crawford et al. (1980), de animal comprovadamente livre de CAEV pelos testes de IDGA, Western blot e PCR, seguindo as normas estabelecidas pelo Comitê de Ética para Uso de Animais da Universidade Estadual do Ceará CEUA/UECE, de acordo com o protocolo de $\mathrm{N}^{\mathrm{o}} 10030861-9$, encaminhado para avaliação na data de 26 de abril de 2010.

Essas células foram inoculadas com cepa padrão CAEV-Cork de título inicial $10^{5,3}$ TCID $50 / \mathrm{mL}$ (Tissue Culture Infectious Dose 50\%), as quais apresentaram um efeito citopático caracterizado por sincícios e lise celular 14 dias após inoculação, sincícios em 50\% dos poços inoculados, conforme os apontamentos de Pinheiro (2010). Os sobrenadantes foram, então, congelados a $-80^{\circ} \mathrm{C}$ e descongelados a $37^{\circ} \mathrm{C}$ por três ciclos consecutivos, clarificados por centrifugação a $3.300 \mathrm{~g}$ a $4^{\circ} \mathrm{C}$ por uma hora e armazenados a $-20^{\circ} \mathrm{C}$ até o momento da purificação.

Após a clarificação, $1.890 \mathrm{~mL}$ de sobrenadante foram submetidos a microfiltrações seriadas com uso de membranas de 100,50 e 10 kilodantons $(\mathrm{kDa})$, respectivamente, utilizando-se o sistema AMICON, modelo 8400 (Millipore ${ }^{\circledR}$ Bedford, MA), com pressão positiva de gás nitrogênio, de acordo com as recomendações do fabricante. Todo o processo foi realizado sob refrigeração, com a finalidade de se evitar a desnaturação das proteínas do antígeno.

Na primeira etapa do processo, solutos acima de $100 \mathrm{kDa}$ foram retidos na câmara. Já a porção abaixo do cut-off da membrana, que saiu no filtrado, foi aproveitada para a próxima etapa de filtração, utilizando-se a membrana seletiva ao peso molecular de $50 \mathrm{kDa}$, que seguiu o mesmo protocolo. Por fim, um total de $50 \mathrm{~mL}$ do concentrado retido na câmara, relativo às porções entre $10 \mathrm{kDa}$ e $50 \mathrm{kDa}$ que correspondem à faixa de peso molecular da proteína alvo p28 de $28 \mathrm{kDa}$, foi posteriormente concentrado por liofilização $2200 \mathrm{Xr}$, se comparado ao volume original. 
A concentração proteica total foi determinada por ensaio colorimétrico, conforme Bradford (1976), utilizando-se albumina sérica bovina (BSA) como padrão. Em seguida, o antígeno purificado, amostras de antígeno ultracentrifugado em colchão de sacarose e o padrão broad-range (14.4 a $97 \mathrm{kDa}$ - LMW Electrophoresis da Pharmacia Biotech ${ }^{\circledR}$ ) foram fracionados por eletroforese em gel de poliacrilamida (SDS-PAGE), segundo Laemmli (1970), com géis de concentração e separação a $4 \%$ e $12,5 \%$, respectivamente. Um dos géis resultantes do processo de eletroforese foi corado usando-se azul de Comassie, segundo Harlon e Lane (1998), para visualização das bandas. Os outros foram submetidos à transferência passiva, em que o gel é colocado entre duas folhas de nitrocelulose (Dura-blot ${ }^{\mathrm{tm}} 0,45 \mu \mathrm{m}$ - SIGMA) e três folhas de papel de filtro, montadas como sanduíche entre duas lâminas de vidro empacotadas com filme plástico e papel alumínio, em tampão de transferência, sob pressão de $12 \mathrm{~kg}$, por três dias, em temperatura ambiente. Decorrido esse tempo, todo o aparato foi desmontado e as membranas foram coradas com corante Ponceau S 1X, para se verificar a transferência das proteínas para a membrana (Tesoro-Cruz et al., 2009).

As membranas foram bloqueadas com solução PBS-Tween $0,3 \%$, durante 60 minutos, e lavadas com solução PBS-Tween $0,05 \%$ por cinco minutos, em três ciclos. O soro positivo do kit comercial Caprine Arthritis-Encephalitis/Ovine Progressive Pneumonia Antibody Test Kit (Veterinary Diagnostic Technology, Inc ${ }^{\circledR}$, USA) foi diluído na concentração de 1:100 e adicionado às membranas, sendo incubado por 90 minutos a $37^{\circ} \mathrm{C}$, sob constante agitação. Em seguida, as membranas foram lavadas novamente, como supracitado, para adição do conjugado Anti-Sheep IgG Peroxidase produzido em burro (Sigma-Aldrich, St. Louis, MO), na diluição de 1:1500 em PBS, incubado por 60 minutos. Após, as membranas foram novamente lavadas com solução PBS-Tween $0,05 \%$ e PBS, respectivamente, por duas vezes, durante cinco minutos. A reação de cor foi realizada segundo Tesoro-Cruz (2003), ao abrigo da luz, com adição do substrato DAB/4-Cloronapthol e peróxido de hidrogênio a $30 \%$, parando a reação com água destilada.
A microtécnica de IDGA foi realizada como descrito por Cutlip et al. (1977), com o uso do kit experimental da Embrapa Caprinos e Ovinos, para a averiguação de formação de linhas de precipitação frente à proteína do capsídeo p28 contida no antígeno produzido. A leitura presuntiva foi feita após 48 horas, com posterior leitura confirmativa passadas 72 horas (Pinheiro et al., 2010).

Para determinação das diluições de uso, placas de poliestireno de 96 poços (NUNCMAXISORPTM) foram sensibilizadas por uma hora a $37^{\circ} \mathrm{C}$ e incubadas a $8^{\circ} \mathrm{C}$ overnight, com diluições seriadas de 20 a $0,125 \mu \mathrm{g} / \mathrm{mL}$ de proteína viral em tampão carbonato-bicarbonato $\left(\mathrm{Na}_{2} \mathrm{CO}_{3} \quad 1,7 \mathrm{~g} / \mathrm{L}, \quad \mathrm{NaHCO}_{3} \quad 2,86 \mathrm{~g} / \mathrm{L}, \quad \mathrm{pH} \quad 9,6\right.$ $0,05 \mathrm{M})$, para determinação da concentração ótima do antígeno obtido.

No dia seguinte, as placas foram lavadas com solução PBS-Tween $0,05 \%$ duas vezes e incubadas novamente com solução de bloqueio (caseína $2 \%$ em PBS) por 90 minutos a $37^{\circ} \mathrm{C}$, para que ocorresse o bloqueio dos sítios reativos. Passado esse período, as placas foram novamente lavadas com solução PBS-Tween $0,05 \%$ duas vezes, adicionando-se, em seguida, os soros (positivo, reagente e negativo), em diluições variando de 1:50 a 1:100 do kit de IDGA (Veterinary Diagnostic Technology, Inc ${ }^{\circledR}$, USA), e incubadas por mais $60 \mathrm{~min}$ a $37^{\circ} \mathrm{C}$, a fim de se definir a melhor diluição das amostras.

Continuamente, os poços foram lavados, nessa fase por cinco vezes, e incubados com conjugado DONKEY (Anti-Sheep IgG Peroxidase SIGMA) nas diluições de 1:1000 e 1:1500 por mais uma hora a $37^{\circ} \mathrm{C}$. Em seguida, as placas foram lavadas, como supracitado, por cinco vezes, e reveladas em câmara escura por 18 minutos com substrato OPD (2mg de Ophenylenediamine em presença de $4 \mu \mathrm{L}$ de $\mathrm{H}_{2} \mathrm{O}_{2}$ ) e com $10 \mathrm{~mL}$ de tampão citrato, seguindo-se a adição do ácido sulfúrico $\left(\mathrm{H}_{2} \mathrm{SO}_{4} 4 \mathrm{~N}\right)$ como inibidor da reação, e leitura a $490 \mathrm{~nm} \mathrm{em}$ espectrofotômetro.

A melhor diluição escolhida foi a que apresentou uma diferença maior nas leituras ópticas entre soro positivo e negativo. A padronização do teste seguiu as recomendações da FAO/OIE, com 
soros em duplicata e resultados expressos em densidade óptica (DO) e percentual de positividade (razão entre DO da amostra e controle positivo) (Motha et al., 1994).

Um total de 119 animais comprovadamente negativos pelos testes de IDGA, ELISA e WB com Ag UCCS, provenientes do programa de controle da CAE da Embrapa Caprinos e Ovinos, foi utilizado para a determinação do ponto de corte do teste ELISA. Este corresponde à média do percentual de positividade dos animais negativos somada a três desvios-padrão $(3 \mathrm{SD}+\mathrm{X})$. Da mesma forma, um valor absoluto de 188 soros de animais positivos e negativos, comprovados pela técnica de WB com antígeno UCCS, foi comparado pelos testes do quiquadrado $\left(\chi^{2}\right)$ (Tyler e Cullor, 1989), a fim de se comparar a sensibilidade e a especificidade relativas do Ag UCCS em relação ao $\mathrm{Ag}$ microfiltrado (AgMi), assim como o índice de concordância e o índice Kappa entre os dois resultados (Caquineau et al., 1988).

\section{RESULTADOS}

A concentração do antígeno, após a microfiltração seriada e subsequente liofilização, resultou em um volume final de $800 \mu \mathrm{L}$, correspondendo, aproximadamente, a um volume 2.362 vezes maior que a quantidade inicial. No tocante à dosagem de proteínas totais pelo método de Bradford, o antígeno purificado AgMi mostrou uma concentração de $30,87 \mu \mathrm{g} / \mu \mathrm{L}$.

O padrão eletroforético apresentado pelas proteínas do AgMi mostra um modelo de bandas com pesos moleculares aproximados de 14.4 a $97 \mathrm{kDa}$ (Fig. 1). O antígeno AgMi, com $30,87 \mu \mathrm{g} / \mu \mathrm{L}$, foi diluído para uma concentração final de $20 \mu \mathrm{g} /$ poço, para melhor visualização das bandas. Para o Ag UCCS também foi utilizada essa mesma concentração.

Dentre as proteínas observadas, destacou-se a banda proteica com peso molecular de $28 \mathrm{kDa}$, que demonstrou capacidade antígênica no teste de Western blot (Fig. 2). O teste de WB utilizando AgMi demonstrou que alguns animais apresentaram anticorpos para a porção referente à proteína $\mathrm{p} 28$, mostrando a positividade para a CAE, sendo que esses animais foram testados com a mesma técnica, mas com outro antígeno, de procedência mais onerosa (Ag UCCS), tendo resultado semelhante.

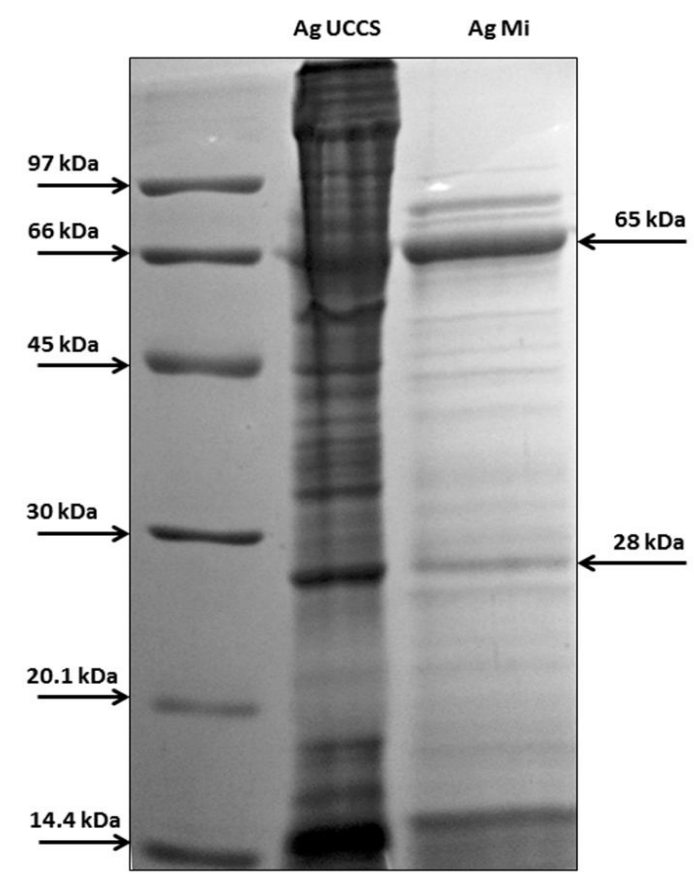

Figura 1. Eletroforese em gel de poliacrilamida (SDS-PAGE). Comparação entre antígeno ultracentrifugado (UCCS) e antígeno microfiltrado (AgMi).

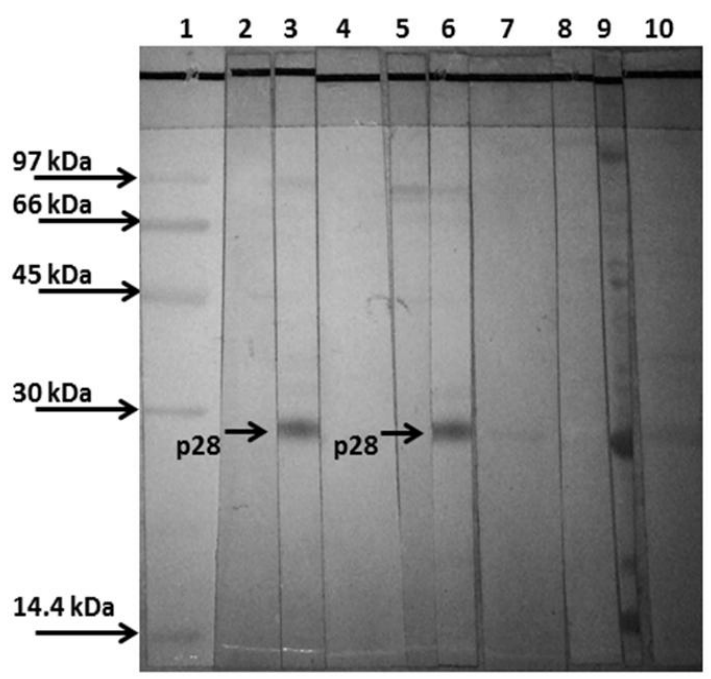

Figura 2. Western blot de antígenos CAEV microfiltrado - AgMi (colunas 2 a 7) e ultracentrifugado - UCCS (colunas 8 a 10). Coluna 1 (padrão de proteína); colunas 2, 5 e 8 (soro caprino negativo); colunas 4, 7 e 10 (soro reagente); colunas 3,6 e 9 (soro positivo). 
A concentração ótima de AgMi, padronizada pela obtenção da maior diferença entre as densidades ópticas (DO) dos soros positivos e negativos, foi de $1 \mu \mathrm{g} /$ poço, com diluição do soro de 1:100 e conjugado de 1:1500. O ponto de corte realizado a partir da análise sorológica de 119 animais comprovadamente negativos foi de 0,352. Desta forma, o teste ELISA indireto realizado a partir de AgMi foi capaz de detectar 88 animais positivos num total de 99 , e 85 animais negativos num total de 89 previamente negativados por WB (AgUCCS), mostrando uma sensibilidade de $95,6 \%$ e especificidade de $88,5 \%$, respectivamente, assim como valor preditivo positivo de $88,9 \%$ e valor preditivo negativo de 96,5\%, com índice Kappa de 0,841, o que demonstrou uma boa concordância entre os testes. Os dados mostraram-se significativos para o qui-quadrado $(\mathrm{P}<0,001)$. A comparação entre o resultado dos testes WB (AgUCCS) e ELISA AgMi é mostrada na Tab. 1.

Tabela 1. Comparação dos resultados entre as técnicas de Western blot (AgUCCS) e ELISA (AgMi)

\begin{tabular}{ccccc}
\hline & \multicolumn{5}{c}{ ELISA } & Total \\
\hline \multirow{3}{*}{ Western blot } & & Positivo & Negativo & 99 \\
& Positivo & 88 & 11 & 89 \\
\cline { 2 - 5 } & Negativo & 4 & 85 & 188 \\
\hline Total & & & & \\
\hline
\end{tabular}

Animais positivos nos testes ELISA e WB $(\mathrm{n}=88)$; negativos no ELISA e no WB $(\mathrm{n}=85)$; positivos no ELISA e negativos no WB $(n=4)$; negativos no ELISA e positivos no WB $(n=11)$. Qui-quadrado entre os testes: 130,23.

\section{DISCUSSÃO}

Um ponto crucial no desenvolvimento de um teste sorológico mais sensível é o processo de purificação do antígeno empregado (Celer e Celer, 2001). Devido à fase precoce da infecção, vários animais infectados, mesmo visivelmente saudáveis, são soronegativos por períodos bastante variados, podendo mostrar uma soroconversão tardia, inexistência ou baixa produção de anticorpos não detectáveis (Brodie et al., 1998).

O teste de referência largamente utilizado ainda é o IDGA, embora este seja de baixa sensibilidade (Knowles et al., 1994). Outras técnicas, como ELISA e WB, tornam-se bastante onerosas, principalmente para o pequeno produtor, por se tratarem de testes que necessitam de kits importados ou de fabricação de antígenos que precisam de uma moderna estrutura laboratorial (Oliveira, 2007).

Western blot ou immunoblot é um teste mais sensível que ELISA, porém possui como desvantagem o fato de ser uma técnica laboriosa e demorada, que necessita da separação das proteínas por eletroforese antes que ocorra a transferência delas para a membrana de nitrocelulose (Pinheiro, 2001), e, como vantagem, a menor ocorrência de reações inespecíficas, o que reduz o aparecimento de resultados falso-positivos e o classifica como o teste complementar, sendo o gold test na validação de outros (Zanoni et al., 1989).

Este trabalho descreve um método simples, prático e menos oneroso para a produção de um antígeno AgMi de alta qualidade para ensaios imunoenzimáticos, quando comparado com Ag UCCS. Esse antígeno, associado à técnica ELISA-i, alia as vantagens do $\mathrm{Ag}$ com a simplicidade do método sorológico, usado no diagnóstico da CAE, pois não exige uso de equipamentos sofisticados, assim como proporciona um bom rendimento dos principais componentes da reação (antígenos e conjugados), com boa sensibilidade e especificidade nos resultados obtidos. O teste de $\mathrm{WB}$, realizado com AgMi, mostrou-se capaz de positivar animais na porção referente à proteína p28, que é identificada como sendo a proteína interna do capsídeo mais abundante e que estimula uma forte reposta humoral durante a infecção (Joag et al., 1996). Esta mesma porção referente à proteína de peso molecular $28 \mathrm{kDa}$ também demonstrou reação positiva (reação de cor) com o uso de outro antígeno, de procedência mais onerosa (AgUCCS). Entretanto, o teste de WB (AgUCCS), embora seja mais dispendioso, 
mostrou-se mais sensível e específico quando comparado ao ELISA-i AgMi, confirmando os resultados de Pinheiro (2001), que também afirma ser ideal, em estudos de prevalência, dispor de duas técnicas como critério independente e seguro para classificar uma população, fato também observado por Celler et al. (1998). Vale salientar ainda, que o antígeno produzido neste trabalho não recebeu nenhum tipo de tratamento especial, sendo constituído apenas de um concentrado de proteínas virais obtido de cultivo celular primário, conferindo a este menor custo e fácil estocagem, o que difere dos protocolos convencionais, como o utilizado por Schroeder et al. (1985).

\section{CONCLUSÕES}

O teste realizado com antígeno produzido por microfiltração seriada para separação da proteína p28 mostrou-se de alta sensibilidade e boa especificidade, podendo ser comparado a outros kits disponíveis no mercado. Pode ser utilizado como teste de diagnóstico seguro para $\mathrm{CAE}$, por apresentar um índice de concordância de 92\% em relação ao teste de Western blot, que utiliza antígeno produzido por meio de técnicas de ultracentrifugação em colchão de sacarose, técnica mais largamente utilizada para certificação de alguns casos duvidosos.

\section{AGRADECIMENTOS}

Ao Laboratório de Virologia da Universidade Estadual do Ceará - UECE, à Empresa Brasileira de Pesquisa Agropecuária - EMBRAPA e à Fundação Cearense de Apoio ao Desenvolvimento Científico e Tecnológico FUNCAP, que financiou este trabalho.

\section{REFERÊNCIAS}

AKERSTROM, B.; BRODIN, T.; REIS, K.; BJORCK, L. et al. Protein G: a powerful tool for binding and detection of monoclonal and polyclonal antibodies. J. Immunol., v.135, p.2589-2592, 1985.

BRADFORD, M.M.A. Rapid and sensitive method for the quantitation of microgram quantities of protein utilizing the principle of protein-dye binding. Anal. Biochem., v.72, p.248-54, 1976.
BRODIE， S.J.; CONCHA-BERMEJILLO, A. DE LA.; SNOWDER, G.D. et al. Current concepts in the epizootiology, diagnosis, and economic importance of ovine progressive pneumonia in North America: A review. Small Rum. Res., v.27, p.1-17, 1998.

CAQUINEAU, L.; DOUART, A.; LECOANET, J. Mice au point dune méthode immunoenzymatique E.L.I.S.A. pour la détection des anticorps anti virus B.V.D. dans le serum des bovines. Rec. Méd. Vét., v.164, p.381-386, 1988.

CELER, V.J.; CELER, V. Detection of antibodies to ovine lentivirus using recombinant capsid and transmembrane proteins. J. Vet. Med. B. Infect. Dis. Vet. Public Health., v.48, p.89-95, 2001.

CELER Jr., V.; CELER, V.; NÉMCOVÁ, H.; ZANONI, R.G. et al. Serologic diagnosis of ovine lentiviruses by whole virus ELISA and IDGA test. Zentralbl. Veterinarmed B., v.45, p.183-188, 1998.

CRAWFORD, T.B.; ADAMS, D.S.; CHEEVERS, W.P.; CORK, L.C. Chronic arthritis in goats caused by a retrovirus. Science, v.207, p.997-999, 1980.

CUTLIP, R.C.; JACKSON, T.A.; LAIRD, G.A. Immunodiffusion test for ovine progressive pneumonia. Am. J. Vet. Res., v.38, p.1081-1084 1977.

HARLON, E.; LANE, D. Antibodies: a laboratory manual. 4. New York:Cold Spring Harbor Laboratory Press, 1988. 726p.

ICTV - International Committee on Taxonomy of Viruses, 2010. Disponível em:

$<$ http://www.ictvdb.rothamsted.ac.uk/ICTVdB// 00.061.1.06.007.htm>. Acessado em: 25 mai. 2011.

JOAG, S.V.; STEPHENS, E.B.; NARAYAN, O. Lentiviruses. In: FIELDS, B.N.; KNIPE, D.M.; HOWLEY, P.M. (Ed.). Virology. Philadelphia: LIPPINCOTT-RAVEN PUBLISHERS, 1996. p.1977-1996.

KEEN, J.; KWANG, J.; ROSATI, S Comparison of ovine lentivirus detection by conventional and recombinant serological methods. Vet. Immunol. Immunopathol., v.47, p.295-309, 1995. 
KNOWLES, D.P.; EVERMANN, J.F.; SHROPSHIRE, C. et al. Evaluation of agar gel immunodiffusion serology using caprine and ovine lentiviral antigens for detection of antibody to caprine arthritis-encephalitis virus. J. Clin. Microbiol., v.32, p.243-245, 1994.

KNOWLES Jr., D.P.; CHEEVERS, W.P.; MCGUIRE, T.C. et al. Severity of arthritis is predicted by antibody response to gp135 in chronic infection with caprine arthritisencephalitis virus. J. Virol., v.64, p.2396-2398, 1990.

KONISHI, M.; NAGURA,Y.; TAKEI, N.; FUJITA, M. et al. Combined eradication strategy for CAE in a dairy goat farm in Japan. Small Rum. Res. v.99, p.65-71, 2011. Disponível em:

$<$ http://www.sciencedirect.com/science/article/B 6TC5-52NC4V5-

1/2/3bac38f6557b66c5a65d3ce5b2dde 83b >.

Acessado em: 14 jul. 2011.

LAEMMLI, U.K. Cleavage of structural proteins during the assembly of the head of bacteriophage T4. Nature, v.227, p.680-685, 1970.

McCONNELL, I.; PETERHANS, E.; ZANONI, R.G. Concordance with reference sera of a recombinant protein ELISA for maedi-visna antibody detection. Vet. Rec., v.142, p.431-433, 1998.

MOTHA, M.X.; RALSTON, J.C. Evaluation of ELISA for detection of antibodies to CAEV in milk. Vet. Microbiol., v.38, p.359-367, 1994.

OLIVEIRA, M.M.M. Diagnóstico e Controle de Lentivirus de Pequenos Ruminantes (LVPR) em Caprinos. 2007. 114f. Tese (Doutorado em Ciência Veterinária) - Departamento de Medicina Veterinária, Universidade Federal Rural de Pernambuco, Recife, PE.

PASICK, J. Maedi-visna virus and caprine arthritis-encephalitis virus: distinct species or quasispecies and its implications for laboratory diagnosis. Can. J. Vet. Res., v.62, p.241-244, 1998.

PETERHANS, E.; GREENLAND, T.; BADIOLA, J. et al. Routes of transmission and consequences of small ruminant lentiviruses (SRLVs) infection and eradication schemes. Vet. Res., v.35, p.257-274, 2004.
PINHEIRO, R.; ANDRIOLI, A.; GOUVEIA, A.M.G. et al. Avaliação de antígenos para o diagnóstico de lentivírus em rebanho caprino sob programa de controle. Arq. Inst. Biol., v.77, p.133-137, 2010.

PINHEIRO, R.R. Vírus de Artrite Encefalite Caprina: Desenvolvimento padronização de ensaios imunoenzimáticos (ELISA e Dot-Blot) e estudo epidemiológico no Estado do Ceará. 2001. 115f. Tese (Doutorado em Ciência Animal) - Escola de Veterinária, Universidade Federal de Minas Gerais, Belo Horizonte.

PUGH, D.G. (Ed). Clínica de ovinos e caprinos. São Paulo: ROCA, 2004, 513p.

SCHROEDER, B.A.; OLIVER, R.E.; CATHCART, A. The development and evaluation of an ELISA for the detection of antibodies to caprine arthritis-encephalitis virus in goat sera. N. Z. Vet. J., v.33, p.213-215, 1985.

SIMARD, C.L.; KIBENGE, M.T.; SINGH, P. et al. Simple and rapid method for production of whole-virus antigen for serodiagnosis of caprine arthritis-encephalitis virus by enzyme-linked immunosorbent assay. Clin. Diagn. Lab. Immunol., v.8, p.352-356, 2001.

SIMARD, C.L.; BRISCOE, M.R. An enzymelinked immunosorbent assay for detection of antibodies to maedi-visna virus in sheep. I. A simple technique for production of antigen using sodium dodecyl sulfate treatment. Can. J. Vet. Res., v.54, p. 446-50, 1990a.

TESORO-CRUZ, E.; HERNÁNDEZGONZÁLEZ， R.; KRETSCHMER-SCHMID, R.; AGUILAR-SETIÉN, A. Cross-reactivity between caprine arthritis-encephalitis virus and type 1 human immunodeficiency virus. Arch. Med. Res., v.34, p.362-6, 2003.

TESORO-CRUZ, E.; FERIA-ROMERO, I.A.; OROZCO-SUÁREZ, S. et al. Frequency of the serological reactivity against the caprine arthritis encephalitis lentivirus gp135 in children who consume goat milk. Arch. Med. Res., v.40, p.204-207, 2009.

TYLER, J.W.; CULLOR, J.S. Titers, tests, and truisms: rational interpretation of diagnostic serologic testing. J. Am. Vet. Med. Assoc., v.194, p.1550-1558, 1989. 


\section{Alves et al.}

ZANONI, R.G.; VOGT, H.R.; POHL, B.; BÖTTCHER, J. et al. An ELISA based on whole virus for the detection of antibodies to small-ruminant lentiviruses. Zentralb. Veterinärmededezin, v.41, p.662-669, 1994.
ZANONI, R.; KRIEG, A.; PETERHANS, E. Detection of antibodies to caprine arthritisencephalitis virus by protein $\mathrm{G}$ enzyme-linked immunosorbent assay and immunoblotting. $J$. Clin. Microbiol., v.27, p.580-582, 1989. 